\title{
Pengaruh Disiplin Dan Motivasi Terhadap Kinerja Karyawan Pada Pt Provices Group Jakarta Selatan
}

\author{
Muhammad Faisal Abdurahman ${ }^{1}$, Lismiatun ${ }^{2 *}$ \\ ${ }^{1}$ Mahasiswa Manajemen (NIM 2016050061) ${ }^{1}$, Universitas Pamulang; faisal.abdurahman25@gmail.com \\ ${ }^{2}$ Fakultas Ekonomi, Universitas Pamulang; dosen01460@unpam.ac.id* \\ Received 16 Februari 2021| Revised 09 Maret 2021 | Accepted 25 Maret 2021 \\ *Korespondensi Penulis
}

\begin{abstract}
Abstrak
Tujuan dari penelitian ini adalah untuk mengetahui Pengaruh Disiplin Dan Motivasi Terhadap Kinerja Karyawan secara bersama-sama pada PT Provices Group Jakarta Selatan. Metode Penelitian yang digunakan dalam penelitian ini bersifat analisa kuantitatif dengan populasi sebanyak 54 orang. Teknik analisis data menggunakan uji validitas, uji realibilitas, uji normalitas, uji multikolionearitas, uji heterokedastisitas, uji regresi linier sederhana, uji regresi linier berganda, koefisien korelasi, koefisien determinasi, uji $\mathrm{F}$ dan uji t. Hasil penelitian ini menunjukkan dua variabel independen yang di uji berpengaruh secara bersama-sama positif dan signifikan terhadap satu variabel dependen melalui uji F, sedangkan angka R Square sebesar 0,272 menunjukkan 27,2\% variasi atas kinerja yang dapat dijelaskan oleh kedua variabel independen tersebut, dimana sisanya 72,8\% dijelaskan oleh variabel lain diluar penelitian ini.
\end{abstract}

Kata kunci: Disiplin; Kinerja Karyawan; Motivasi

\begin{abstract}
The purpose of this study was to determine the effect of discipline and motivation on employee performance together at PT Provices Group, South Jakarta. The research method used in this research is quantitative analysis with a population of 54 people. The data analysis technique in this study used validity test, reliability test, normality test, multicollionearity test, heteroscedasticity test, simple linear regression test, multiple linear regression test, correlation coefficient, determination coefficient, $F$ test and test. The results of this study indicate that the two independent variables tested have a positive and significant effect on one dependent variable through the $F$ test, while the $R$ Square number of 0.272 shows $27.2 \%$ of the variation in performance that can be explained by the two independent. Where the remaining $72.8 \%$ is explained by other variables outside of this study. The results of the study indicate that Discipline and Motivation simultaneously have a positive influence on employee performance at PT Provices Group South Jakarta.
\end{abstract}

Keywords: Discipline; Employee Performance; Motivation 


\section{PENDAHULUAN}

Organisasi yang baik adalah organisasi yang berusaha meningkatkan kemampuan sumber daya manusianya, karena hal tersebut merupakan faktor kunci utama meningkatkan kinerja karyawan. Kualitas dan kuantitas produk atau jasa sangat tergantung pada sumber daya yang ada pada perusahaan. Upaya peningkatan kinerja perusahaan tidak hanya mengandalkan pada mesin modern, modal dan bahan baku. Faktor lain yang perlu diperhatikan adalah faktor tenaga kerja, yang dalam hal ini adalah manusia. Upaya untuk meningkatkan hasil yang maksimal untuk perusahaan adalah dengan meningkatkan kinerja karyawan. Dengan peningkatan tersebut, maka diharapkan kinerja karyawan dapat tercapai dengan efektif dan efisien. Manajemen merupakan suatu proses untuk melaksanakan fungsi-fungsi perencanaan, pengorganisasian, pengarahan, dan pe-ngendalian untuk mencapai tujuan yang telah di tetapkan. Adapun yang diatur merupakan unsur-unsur manajemen yang terdiri dari man, money, methods, machines, materials, dan market. Penyampaian disiplin kerja perlu juga di sinergikan dengan tuntutan kompetensi dan motivasi, oleh karena itu dimensi daya saing dalam SDM semakin menjadi faktor penting sehingga upaya memacu kualitas SDM yang memiliki disiplin kerja yang baik merupakan tuntutan yang harus di kedepankan.

Menurut Wibowo (2017:2) "mendefinisikan manajemen adalah proses penggunaan sumber daya organisasi dengan menggunakan orang lain untuk mencapai tujuan organisasi secara efektif dan efisien". Hasibuan (2016:9) "berpendapat bahwa manajemen adalah ilmu dan seni mengaur proses pemanfaatan sumber daya manusia dan sumbersumber lainnya secara efektif dan efisien untuk mencapai suatu tujuan tertentu".

Menurut Afandi (2018:1) "berpendapat manajemen adalah bekerja dengan orang-orang untuk mencapai tujuan organisasi dengan pelaksanaan fungsi perencanaan (planning), pengorganisasian (organizing), penyusunan personalia atau kepegawaian (staffing), pengarahan dan kepemimpinan (leading), dan pengawasan (controlling). Manajemen adalah suatu proses khas, yang terdiri dari tindakan perencanaan, pengorganisasian, pergerakan, dan pengendalian yang dilakukan untuk menentukan serta mencapai sasaran-sasaran yang telah ditentukan melalui pemanfaatan sumber daya manusia dan sumber-sumber daya lainnya".

PT Provices Group merupakan perusahaan yang bergerak dalam bidang jasa pengelolaan properti seperti menyediakan nasehat atau pertimbangan, penilaian atau penetapan biaya, rencana penyerahan mulai dari pengoperasian bangunan, hubungan antar penyewa atau penghuni, pengelolaan parkir, pemeliharaan pertamanan, kebersihan, keamanan, administrasi atau resepsionis, sampai dengan manajemen keuangan. Dalam penelitian ini dikhususkan hanya pada bidang pemeliharaan pertamanan, kebersihan dan keamanan yang berlokasi di Jl Hang Lekir II No. 16 Kebayoran Baru, Jakarta Selatan.

Hasil penelitian ini akan menjadi penting dimana perusahaan ini mengharuskan karyawannya memiliki kinerja yang baik dikarenakan PT Provices Group mengutamakan kepuasan Client nya dan mengutamakan ketepatan waktu, kerja tuntas dalam target yang di rencanakan, dalam salah satu upaya memberikan pelayanan yang baik terhadap Client dalam memenuhi permintaan dan kebutuhan Client. Tanpa adanya kinerja yang baik perusahaan tidak akan berjalan dengan baik dalam memenuhi segala tuntutan Client nya.

Tabel 1. Data Absensi Karyawan PT Provices Group Jakarta Selatan Tahun 2017-2019

\begin{tabular}{|c|l|c|c|c|}
\hline Tahun & \multicolumn{1}{|c|}{ Bulan } & Total & Terlambat & Persentase \\
\hline \multirow{8}{*}{2017} & Januari & 54 & 15 & $28 \%$ \\
\cline { 2 - 5 } & Februari & 54 & 16 & $30 \%$ \\
\cline { 2 - 5 } & Maret & 54 & 12 & $22 \%$ \\
\cline { 2 - 5 } & April & 54 & 20 & $37 \%$ \\
\cline { 2 - 5 } & Mei & 54 & 15 & $28 \%$ \\
\cline { 2 - 5 } & Juni & 54 & 14 & $26 \%$ \\
\cline { 2 - 5 } & Juli & 54 & 14 & $26 \%$ \\
\cline { 2 - 5 } & Agustus & 54 & 13 & $24 \%$ \\
\cline { 2 - 5 } & September & 54 & 16 & $30 \%$ \\
\cline { 2 - 5 } & Oktober & 54 & 12 & $22 \%$ \\
\cline { 2 - 5 } & November & 54 & 12 & $22 \%$ \\
\cline { 2 - 5 } & Desember & 54 & 14 & $26 \%$ \\
\hline
\end{tabular}




\begin{tabular}{|c|c|c|c|c|}
\hline Tahun & Bulan & Total & Terlambat & Persentase \\
\hline \multirow{12}{*}{2018} & Januari & 54 & 12 & $22 \%$ \\
\hline & Februari & 54 & 10 & $19 \%$ \\
\hline & Maret & 54 & 14 & $26 \%$ \\
\hline & April & 54 & 12 & $22 \%$ \\
\hline & Mei & 54 & 13 & $24 \%$ \\
\hline & Juni & 54 & 14 & $26 \%$ \\
\hline & Juli & 54 & 15 & $28 \%$ \\
\hline & Agustus & 54 & 11 & $20 \%$ \\
\hline & September & 54 & 9 & $17 \%$ \\
\hline & Oktober & 54 & 13 & $24 \%$ \\
\hline & November & 54 & 11 & $20 \%$ \\
\hline & Desember & 54 & 11 & $20 \%$ \\
\hline \multirow{12}{*}{2019} & Januari & 54 & 10 & $19 \%$ \\
\hline & Februari & 54 & 12 & $22 \%$ \\
\hline & Maret & 54 & 5 & $9 \%$ \\
\hline & April & 54 & 12 & $22 \%$ \\
\hline & Mei & 54 & 11 & $20 \%$ \\
\hline & Juni & 54 & 10 & $19 \%$ \\
\hline & Juli & 54 & 10 & $19 \%$ \\
\hline & Agustus & 54 & 14 & $26 \%$ \\
\hline & September & 54 & 12 & $22 \%$ \\
\hline & Oktober & 54 & 11 & $20 \%$ \\
\hline & November & 54 & 9 & $17 \%$ \\
\hline & Desember & 54 & 13 & $24 \%$ \\
\hline
\end{tabular}

Sumber : Absensi Karyawan PT Provices Group Jakarta Selatan 2020

Berdasarkan pada tabel absensi diatas, menunjukan bahwa hal ini membuktikan karyawan masih kurang disiplin dalam waktu kerja pada setiap bulannya dan masih ada karyawan yang terlambat dan mangkir terhadap standar operasional perusahaan yang telah di tentukan.

Tabel 2. Target Kinerja karyawan PT Provices Group Jakarta Selatan Tahun 2017-2019

\begin{tabular}{ccccccccc}
\hline & 2017 & \multicolumn{1}{c}{2018} & \multicolumn{3}{c}{2019} \\
\hline T & TT & $\begin{array}{c}\text { P } \\
(\%)\end{array}$ & T & TT & $\begin{array}{c}\text { P } \\
(\%)\end{array}$ & T & TT & $\begin{array}{c}\text { P } \\
(\%)\end{array}$ \\
\hline 25 & 18 & 72 & 25 & 16 & 64 & 25 & 22 & 88
\end{tabular}

Sumber : Dokumentasi PT Provices Group Jakarta Selatan 2020

Pada tabel tersebut menunjukan bahwa target dan persentase yang paling tertinggi adalah di tahun 2019 yaitu mencapai 88\%, namun pada persentase yang paling terendah yaitu berada ditahun 2018 dengan persentase 64\%. Dengan target yang ditentukan oleh PT Provices Group yaitu dari 25 properti yang harus dikelola pertahunnya yang harus terealisasikan.

Penelitian ini bertujuan untuk menganalisa "Pengaruh Disiplin Dan Motivasi Terhadap Kinerja Karyawan Pada PT Provices Group Jakarta Selatan". Sehingga dapat diketahui tingkat disiplin, kesadaran karyawan akan pentingnya prestasi, kurangnya ketepatan waktu dalam melakukan pekerjaan yang telah di intruksikan oleh pimpinan, kurang puasnya dengan upah yang diberikan perusahaan, sampai kualitas dan kuantitas kerja yang menurun pada PT Provices Group Jakarta Selatan.

\section{Disiplin Kerja}

Pengertian disiplin menurut Sutrisno (2017:86) "disiplin kerja dapat dilihat sebagai sesuatu yang besar manfaatnya, baik bagi kepentingan organisasi maupun bagi para karyawan. Bagi organisasi adanya disiplin kerja akan menjamin terpeliharanya tata tertib dan kelancaran pelaksanaan tugas, sehingga diperoleh hasil yang optimal". "Disiplin kerja adalah kesadaran dan kesediaan seseorang mentaati semua peraturan perusahaan dan norma-norma sosial yang berlaku. Kesadaran adalah sikap seseorang yang secara sukarela mentaati semua peraturan dan sadar akan tugas dan tanggung jawabnya, jadi ia akan mematuhi atau mengerjakan semua tugasnya dengan baik, bukan atas paksaan" (Menurut Hasibuan, 2017:193). Menurut Rivai (2015:599) “Disiplin kerja adalah suatu alat yang digunakan para manajer untuk berkomunikasi dengan karyawan agar mereka bersedia untuk mengubah suatu perilaku serta sebagai suatu upaya untuk meningkatkan kesadaran dan kesediaan seseorang mentaati semua peraturan perusahaan dan norma-norma sosial yang berlaku".

\section{Motivasi}

Pengertian Motivasi menurut Mangkunegara (2015:93) "Motivasi adalah kondisi yang menggerakan pegawai agar mampu mencapai tujuan dari motifnya, motif merupakan suatu dorongan kebutuhan dalam diri pegawai yang perlu dipenuhi agar pegawai tersebut dapat menyesuaikan diri dengan lingkungannya”. Menurut Rivai (2015:607) "Motivasi adalah serangkaian sikap dan nilainilai yang mempengaruhi individu untuk mencapai hal spesifik sesuai dengan tujuan individu. Sikap dan nilai tersebut merupakan suatu yang invisibel yang memberikan kekuatan 
untuk mendorong individu bertingkah laku dalam menacapai tujuan". "Motivasi adalah dorongan seseorang untuk melakukan kegiatankegiatan, menciptakan kegairahan kerja seseorang, agar mereka mau bekerja sama, bekerja efektif dan terintegrasi dengan segala daya upayanya untuk mencapai kepuasan tertentu guna mencapai tujuan" (Menurut Mujid (Skripsi Universitas Pamulang 2019:28).

\section{Kinerja Karyawan}

Menurut Sedarmayanti (2016:260) "mengungkapkan bahwa, kinerja merupakan terjemahan dari performance yang berarti hasil kerja seorang pekerja, sebuah proses manajemen atau suatu organisasi secara keseluruhan, dimana hasil kerja tersebut harus ditunjukan buktinya secara konkrit dan dapat diukur (dibandingkan dengan standar yang telah ditentukan)". Menurut Wibowo (2016:7) "mengemukakan bahwa kinerja adalah tentang melakukan pekerjaan dan hasil yang dicapai dari pekerjaan tersebut". Menurut Anwar Prabu Mangkunegara (2015:67) "kinerja adalah hasil kerja secara kualitas dan kuantitas yang dicapai oleh seorang pegawai dalam melaksanakan tugasnya sesuai dengan tanggungjawab yang diberikan kepadanya".

\section{Penelitian Terdahulu}

Penelitian Eman Sulaeman (2018) yang berjudul "Pengaruh Disiplin Kerja, Motivasi dan Budaya Organisasi Terhadap Kinerja Karyawan Pada PT Bank Maybank Indonesia, TBK. Cabang Pondok Indah" diperoleh hasil Disiplin kerja, Motivasi dan Budaya organisasi secara simultan berpengaruh positif dan signifikan terhadap kinerja karyawan dengan kontribusi pengaruh sebesar 49,6\%.

Penelitian I Nyoman Marayasa dan Anggi Faradila (2019) yang berjudul "Pengaruh Motivasi dan Disiplin Kerja Terhadap Kinerja Karyawan PT Bank Dinar Indonesia” diperoleh hasil Motivasi dan disiplin kerja secara bersama-sama ber-pengaruh positif dan signifikan terhadap kinerja karyawan PT Bank Dinar Indonesia.
Penelitian Aji Indra Putra (2019) yang berjudul "Pengaruh Motivasi dan Disiplin terhadap kinerja Karyawan Pada PT Bank OCBC NISP Jakarta Selatan.” Diperoleh hasil terdapat pengaruh yang positif dan signifikan antara motivasi dan disiplin secara bersamasama terhadap kinerja karyawan.

Penelitian Mujid (2019) yang berjudul "Pengaruh Motivasi dan Disiplin Kerja Terhadap Kinerja Karyawan pada PT Bahtera Adi Jaya Tangerang". Dari hasil penelitian, penulis menyimpulkan adanya pengaruh yang positif dan signifikan antara motivasi dan disiplin terhadap kinerja karyawan pada PT Bahtera Adi Jaya Tangerang.

\section{Kerangka Berpikir}

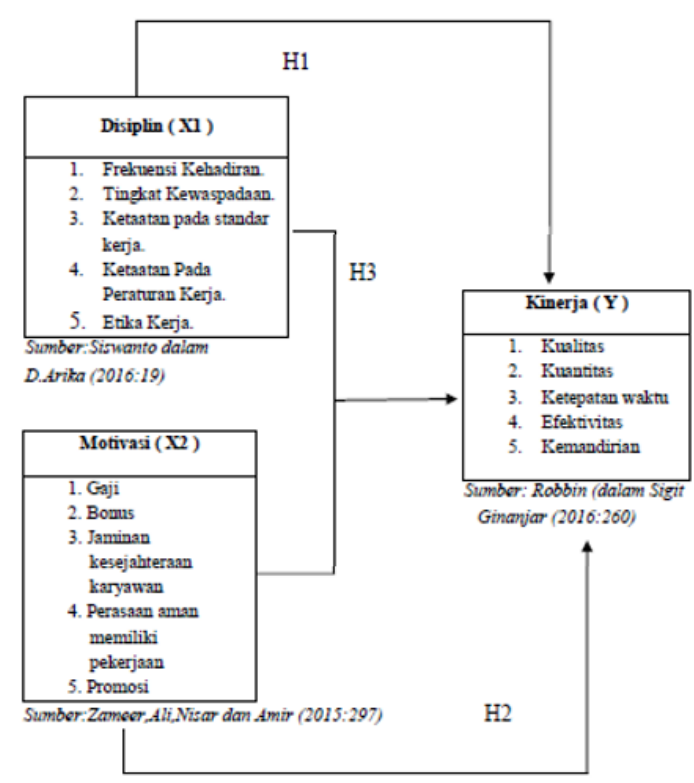

Gambar 1. Kerangka Berpikir Penelitian

\section{Hipotesis}

Hipotesis yang akan dibuktikan dalam penelitian ini adalah :

$\mathrm{H}_{1}=$ Diduga terdapat pengaruh disiplin terhadap kinerja pada PT Provices Group Jakarta Selatan

$\mathrm{H}_{2}=$ Diduga terdapat pengaruh motivasi terhadap kinerja karyawan pada PT Provices Group Jakarta Selatan

$\mathrm{H}_{3}=$ Diduga terdapat pengaruh disiplin dan motivasi secara simultan terhadap kinerja 
karyawan pada PT Provices Group Jakarta Selatan.

\section{METODE}

Metode penelitian yang digunakan pada penelitian ini adalah dengan analisa kuantatif. Sugiyono (2017:148) "mendefinisikan metode penelitian kuantatif dapat diartikan sebagai metode penelitian yang berlandaskan pada filsafat positivme, digunakan untuk meneliti pada populasi atau sampel tertentu, tekhnik pengambilan sampel pada umumnya dilakukan secara random". Dalam penelitian ini sampel yang diambil adalah semua karyawan PT Provices Group Jakarta Selatan sebanyak 54 orang responden yang disebut dengan sampel jenuh.

\section{HASIL DAN PEMBAHASAN}

\section{Uji Normalitas}

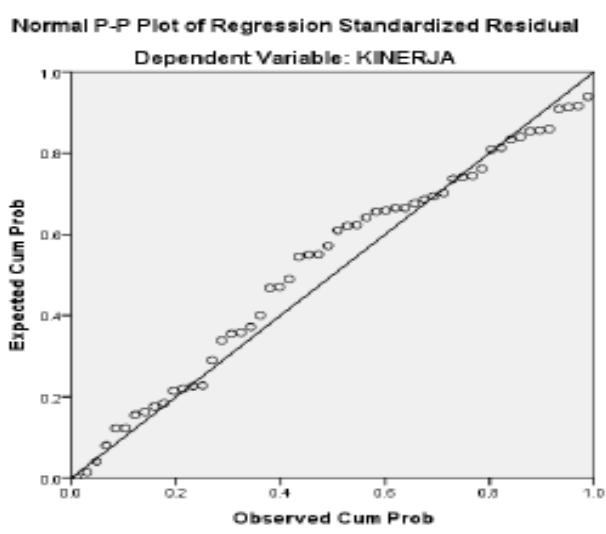

Gambar 2. Hasil Uji Normal P-Plot

Sumber : Data diolah, 2021

Berdasarkan gambar di atas, normal probability plot menghasilkan data berdistribusi normal. Dapat dilihat bahwa titik-titik menyebar dan mendekati garis diagonal sehingga dapat disimpulkan bahwa model regresi memenuhi asumsi normalitas.

\section{Uji Multikolinieritas}

Tabel 3. Hasil Uji Multikolinieritas

\begin{tabular}{|c|c|c|}
\hline \multirow[b]{2}{*}{ Model } & \multicolumn{2}{|c|}{ Collinearity Statistics } \\
\hline & Tolerance & VIF \\
\hline (Constant) & & \\
\hline Disiplin Kerja & 928 & ,078 \\
\hline
\end{tabular}

\begin{tabular}{lrr}
\hline Motivasi Kerja $\quad, 928$ & 1,078 \\
\hline a. Dependent Variable: Kinerja
\end{tabular}

Hasil uji multikolinieritas di atas menunjukkan bahwa semua variabel bebas mempunyai nilai VIF lebih kecil dari 10 (VIF < 10) dan nilai tolerance lebih besar dari 0,10 (tolerance < 10), dapat disimpulkan bahwa variabel independent terbebas dari asusmsi multikolinieritas.

\section{Uji Heterokedastisitas}

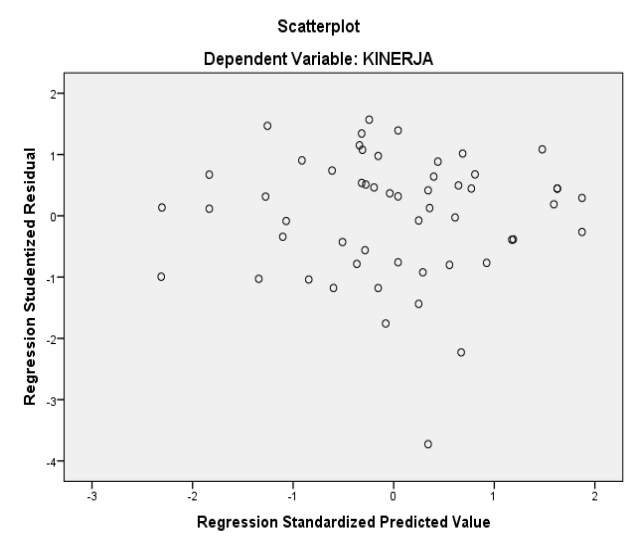

Gambar 3. Hasil Uji Heterokedastisitas Sumber : Data diolah, 2021

Dari grafik scatterplot di atas dapat dilihat bahwa tidak ada pola tertentu karena titik menyebar tidak beraturan di atas dan di bawah sumbu 0 pada sumbu Y dan tidak membentuk sebuah pola yang jelas. Maka dapat disimpulkan bahwa tidak terdapat gejala heterokedastisitas dalam penelitian ini.

\section{Uji Analisis Regresi Berganda}

Tabel 4. Uji Analisis Regresi berganda

\section{Coefficients $^{\mathrm{a}}$}

\begin{tabular}{|c|c|c|c|c|c|c|}
\hline & \multirow[b]{2}{*}{ Model } & \multicolumn{2}{|c|}{$\begin{array}{c}\text { Unstandardized } \\
\text { Coefficients }\end{array}$} & $\begin{array}{l}\text { Standardized } \\
\text { Coefficients }\end{array}$ & \multirow{2}{*}{$\mathrm{t}$} & \multirow{2}{*}{ Sig. } \\
\hline & & B & $\begin{array}{l}\text { Std. } \\
\text { Error }\end{array}$ & Beta & & \\
\hline \multirow[t]{3}{*}{1} & (Constant) & 11.561 & 3.522 & & 3.283 & .002 \\
\hline & Disiplin Kerja & 1.593 & .351 & 1.590 & 4.544 & .000 \\
\hline & Motivasi & -.862 & .379 & -.795 & -2.271 & .208 \\
\hline
\end{tabular}

a. Dependent Variable: Kinerja

Sumber : Data diolah, 2021

Hasil uji regresi berganda diperoleh persamaan regresi $\mathbf{Y}=\mathbf{2 7 , 2 2 0}+\mathbf{0 , 4 4 7} \mathbf{X}_{\mathbf{1}}+$ $\mathbf{0 , 0 9 3} \mathrm{X}_{2}$, interpretasi model tersebut:

a. Nilai konstanta sebesar 27,220 artinya apabila variabel independennya sama 
dengan nol maka variabel kinerja bernilai sebesar 27,220.

b. Nilai koefisien disiplin kerja sebesar 0,447 dapat diartikan bahwa setiap penambahan 1 satuan, maka disiplin kerja akan naik sebesar 0,447 satuan jika variabel lain tetap.

c. Nilai koefisien motivasi sebesar 0,093 dapat diartikan bahwa setiap penambahan 1 satuan, maka motivasi akan naik sebesar 0,093 satuan jika variabel lain tetap.

\section{Uji Koefisien Korelasi dan Determinasi $\left(\mathbf{R}^{2}\right)$} Tabel 5. Hasil Analisis

Koefisien Korelasi dan Determinasi

Model Summary ${ }^{\mathrm{b}}$

\begin{tabular}{ccccc} 
Model & $\mathrm{R}$ & $\begin{array}{c}\mathrm{R} \\
\text { Square }\end{array}$ & $\begin{array}{c}\text { Adjusted } \mathrm{R} \\
\text { Square }\end{array}$ & $\begin{array}{c}\text { Std. Error } \\
\text { of the } \\
\text { Estimate }\end{array}$ \\
\hline 1 &, $522^{\mathrm{a}}$ &, 272 &, 244 & 3,760 \\
\hline
\end{tabular}

a. Predictors: (Constant), Motivasi, Disiplin Kerja

b. Dependent Variable: Kinerja

Sumber : Data diolah, 2021

Pada tabel 5. Diperoleh nilai koefisien korelasi sebesar 0,522, yangmenunjukkan bahwa korelasi atau hubungan antara kinerja dengan disiplin kerja mempunyai tingkat hubungan yang sedang. Sedangkan nilai $\mathrm{R}$ square adalah 0,272 , menunjukan persentase pengaruh variabel disiplin dan motivasi terhadap kinerja sebesar $27,2 \%$ sedangkan sisanya 72,8\% dipengaruhi variabel lain.

\section{Uji Parsial (uji t )}

Uji statistik (uji t) bertujuan untuk menunjukan seberapa jauh pengaruh satu variabel independen dalam menerangkan variasi variabel dependen atau untuk menguji variabel bebas secara parsial (individu).

Tabel 6. Hasil Uji Persial Coefficients $^{\mathrm{a}}$

\begin{tabular}{|c|c|c|c|c|c|}
\hline \multirow[b]{2}{*}{ Model } & \multicolumn{2}{|c|}{$\begin{array}{c}\text { Unstandardized } \\
\text { Coefficients }\end{array}$} & $\begin{array}{c}\text { Standardized } \\
\text { Coefficients }\end{array}$ & \multirow{2}{*}{$\mathrm{t}$} & \multirow{2}{*}{ Sig. } \\
\hline & B & $\begin{array}{l}\text { Std. } \\
\text { Error }\end{array}$ & Beta & & \\
\hline 1 (Constant) & 27,220 & 5,005 & & 5,439 & .000 \\
\hline Disiplin Kerja &, 447 & .121 & ,457 & 3,685 & .000 \\
\hline Motivasi & ,093 & .073 & ,158 & 1,275 & .208 \\
\hline
\end{tabular}

a. Dependent Variable: Kinerja

Sumber : Data diolah, 2021
Berdasarkan tabel di atas dapat diambil kesimpulan sebagai berikut:

Variabel disiplin kerja mempunyai tingkat signifikasi sebesar 0,000 nilai ini lebih kecil dari $0,05(0,000<0,05)$ dengan nilai $t$ hitung 3,685 > 2,007. Hal ini berarti $\mathrm{H} 1$ diterima. Sehingga dapat dikatakan bahwa disiplin kerja berpengaruh signifikan terhadap kinerja karyawan.

Variabel motivasi mempunyai tingkat signifikasi sebesar 0,208 nilai ini lebih besar dari $0,05(0,208>0,05)$ dengan nilai t-hitung $1,275<2,007$. Hal ini berati $\mathrm{H} 2$ ditolak. Sehingga dapat dikatakan bahwa motivasi tidak berpengaruh signifikan terhadap kinerja karyawan.

\section{Uji Simultan (F)}

Uji statistik (F) bertujuan untuk menunjukkan apakah semua variabel bebas atau independen yang dimasukkan dalam model regresi mempunyai pengaruh yang signifikan secara bersama-sama terhadap variabel terikat atau dependen.

Tabel 7. Hasil Uji F (Simultan)

\begin{tabular}{|c|c|c|c|c|c|c|}
\hline \multicolumn{7}{|c|}{$\mathrm{ANOVA}^{\mathrm{a}}$} \\
\hline \multicolumn{2}{|c|}{ Model } & $\begin{array}{l}\text { Sum of } \\
\text { Squares }\end{array}$ & Df & $\begin{array}{l}\text { Mean } \\
\text { Square }\end{array}$ & $\mathrm{F}$ & Sig. \\
\hline \multirow[t]{3}{*}{1} & Regression & 269,972 & 2 & 134,986 & 9,550 &, $000^{\mathrm{b}}$ \\
\hline & Residual & 720,861 & 51 & 14,135 & & \\
\hline & $\overline{\text { Total }}$ & 990,833 & 53 & & & \\
\hline
\end{tabular}

a. Dependent Variable: Kinerja

b. Predictors: (Constant), Motivasi, Disiplin Kerja

Sumber : Data diolah, 2021

Dari tabel di atas dapat diketahui bahwa nilai $\mathrm{F}$-hitung sebesar 9,550 sedangkan $\mathrm{F}_{\text {-tabel }}$ sebesar 3,18, maka 9,550>3,18. Dengan demikian dan secara statistik diperoleh dengan nilai signifikan $0,000<0,050$. Dari data tersebut dapat diartikan bahwa hipotesis diterima. Hal ini menunjukkan bahwa disiplin dan motivasi secara simultan mempunyai pengaruh yang signifikan terhadap kinerja karyawan.

\section{Pembahasan}

Hasil pengujian hipotesis kedua $\left(\mathrm{H}_{1}\right)$, terbukti bahwa disiplin berpengaruh signifikan terhadap kinerja karyawan. Dimana dalam uji t 
didapatkan hasil nilai $\mathrm{t}$-hitung untuk disiplin sebesar 3,685 lebih besar dibandingkan nilai $\mathrm{t}_{\text {tabel }}$ sebesar 2,007. Hasil pengujian hipotesa yang dilakukan mendukung penelitian sebelumnya mengenai pengaruh disiplin terhadap kinerja karyawan yaitu Novelisa. P, Budiman, Vonne S. Saerang, Greis M. Sendow (2016) secara parsial variabel disiplin berpengaruh signifikan terhadap kinerja karyawan.

Hasil pengujian hipotesis kedua $\left(\mathrm{H}_{2}\right)$, terbukti bahwa motivasi tidak berpengaruh signifikan terhadap kinerja karyawan berdasarkan penelitian. Dimana dalam uji t didapatkan hasil nilai t-hitung untuk motivasi sebesar 1,275 lebih kecil dibandingkan nilai $t$-tabel sebesar 2,007. Hasil pengujian hipotesa yang dilakukan mendukung penelitian sebelumnya mengenai pengaruh motivasi terhadap kinerja karyawan yaitu Mujid (2019).

Hasil pengujian hipotesis ketiga $\left(\mathrm{H}_{3}\right)$, terbukti bahwa disiplin dan motivasi bersamasama atau simultan berpengaruh signifikan terhadap kinerja berdasarkan hasil penelitian, dimana dalam uji $\mathrm{F}$ didapatkan hasil $\mathrm{F}_{\text {-hitung }}$ untuk variabel disiplin dan motivasi secara bersama-sama atau simultan adalah sebesar 9,550 lebih besar disbanding $\mathrm{F}_{- \text {tabel }}$ sebesar 3,18. Selain hal tersebut diatas dalam uji $\mathrm{F}$ juga diperoleh hasil sig $\alpha$ untuk variabel disiplin dan motivasi adalah sebesar 0,000 lebih kecil dari nilai alpha sebesar 0,05 . Hasil pengujian hipotesa yang dilakukan mendukung penelitian sebelumnya mengenai pengaruh disiplin dan motivasi terhadap kinerja karyawan yaitu I Nyoman Marayasa dan Anggi Faradila (2019).

\section{SIMPULAN}

Berdasarkan data yang diperoleh dan hasil analisis penelitian menyimpulkan sebagai berikut :

Terdapat pengaruh positif dan signifikan disiplin terhadap kinerja karyawan ditujukan dengan nilai t-hitung sebesar 3,685 yang berarti $\mathrm{t}$-hitung lebih besar dari $\mathrm{t}$-tabel $(3,685>2,007)$ dengan tingkat signifikan sebesar 0,000 . Nilai signifikan lebih kecil dari $0,05(0,000<0,05)$.
Motivasi tidak berpengaruh signifikan terhadap kinerja karyawan ditunjukan dengan nilai sebesar 1,275 berarti t-hitung lebih kecil dari $\mathrm{t}_{\text {-tabel }}$ sebesar $(1,275<2,007)$ dengan tingkat signifikan sebesar 0,208 . Nilai signifikan lebih besar dari $0,05(0,208>0,05$.

Terdapat pengaruh positif dan signifikan disiplin dan motivasi secara simultan terhadap kinerja karyawan. Hal ini berdasarkan analisis berganda diperoleh nilai $\mathrm{F}_{\text {-hitung }}$ sebesar 9,550 sedangkan $\mathrm{F}_{\text {-tabel }} 3,18$, maka $9,550>3,18$.

\section{DAFTAR PUSTAKA}

Afandi, P. (2018). Manajemen Sumber Daya Manusia (teori, konsep dan indikator). Riau:Zanafap Publishing

Eman Sulaeman . (2018). Pengaruh disiplin kerja, motivasi dan budaya organi-sasi Terhadap kinerja karyawan. Jurnal Disrupsi Bisnis. Vol. 01, No.2 ISSN:2621-797X

Hasibuan, Malayu S.P. (2016). Manajemen Sumber Daya Manusia. Jakarta:Bumi Aksara

I Nyoman Marayasa, Anggi Faradila. (2019). Pengaruh Motivasi dan Disiplin Kerja Terhadap Kinerja Karyawan. Jurnal Ekonomi Efektif. Vol. 2, No ISSN:26228882

Mangkunegara, A.A Prabu Anwar. (2015). Manajemen Sumber Daya Manusia. Bandung:PT.Remaja Rosdakarya

Mujid. (2019). Dalam Skripsi Universitas Pamulang Pengaruh motivasi dan disiplin kerja terhadap kinerja karyawan. Tangerang

Novelisa P, Budiman, Vonne S. Saerang, Greis M. Sendow. (2016). Pengaruh Kompetensi, Motivasi, Dan Disiplin Kerja Terhadap Kinerja Karyawan. Jurnal EMBA. Vol. 4, No.4, ISSN:2303-1174

Robbin, Stephen P. (2016). Perilaku Organisasi. Jakarta: PT. Indeks Kelompok Gramedia 
M.Faisal Abdurahman \& Lismiatun: Pengaruh Disiplin Dan Motivasi Terhadap Kinerja Karyawan Pada Pt Provices Group Jakarta Selatan

Sedarmayanti. (2016). Sumber Daya

Manusia. Bandung:PT. Refika

Aditama

Sutrisno, Edy. (2017). Manajemen Sumber

Daya Manusia. Jakarta:Kencana

Vithzal, Rivai. (2015). Manajemen Sumber Daya Manusia Untuk Perusahaan. Jakarta:PT. Raja Grafindo Persada

Wibowo. (2017). Manajemen Kinerja. Depok: PT. Raja Grafindo Persada

Zamer, Hashim, Shehzad Ali, Waqar Nisar dan Muhammad Amir. (2015). The Impact Of The Motivation On The Employee's Performance in Beverage Industry of Pakistan. International Journal of Academic Research in Accounting, Finance and Management Sciences Vol.4, No.1 